\title{
Tree rainfall interception measured by stem compression
}

\author{
J. Friesen, ${ }^{1}$ C. van Beek, ${ }^{2}$ J. Selker, ${ }^{3}$ H. H. G. Savenije, ${ }^{1}$ and N. van de Giesen ${ }^{1}$ \\ Received 4 April 2008; revised 15 September 2008; accepted 22 September 2008; published 13 December 2008.
}

[1] A method for measuring whole-tree interception of precipitation is presented which employs mechanical displacement sensors to measure trunk compression caused by the water captured by the tree. This direct and nondestructive method is demonstrated to be sensitive to less than $5 \mathrm{~kg}$ of interception field tests in Netherlands and Ghana.

Citation: Friesen, J., C. van Beek, J. Selker, H. H. G. Savenije, and N. van de Giesen (2008), Tree rainfall interception measured by stem compression, Water Resour. Res., 44, W00D15, doi:10.1029/2008WR007074.

\section{Introduction}

[2] Trees and woody plant species are significant in hydrologic processes most directly through transpiration and evaporation. Canopy interception has been found to be as high as $60 \%$ of annual rainfall [Forgeard et al., 1980]; internal vegetation water fluxes have been widely studied using sap flow techniques [Granier, 1987; Green and Clothier, 1988; Oguntunde and van de Giesen, 2005; Savenije, 2004; Sevanto et al., 2001]. In this paper, we present a new nondestructive, in situ approach to monitor water held above ground in and on trees.

[3] Beyond traditional net rainfall measurements [e.g., Navar and Bryan, 1990] canopy interception has been measured by (1) artificial wetting of vegetative surfaces [e.g., Aston, 1979; Keim et al., 2006; Llorens and Gallart, 2000], (2) the cantilever deflection method [e.g., Hancock and Crowther, 1979; Huang et al., 2005], (3) ray attenuation methods [e.g., Bouten et al., 1991], and (4) weighing lysimeters [e.g., Edwards, 1986; Fritschen et al., 1973; Storck et al., 2002]. With the exception of the fourth technique, these measurement techniques are all either indirect or employ a partial canopy and must be upscaled on the basis of assumed whole-canopy behavior.

[4] Changes in aboveground tree mass due to interception (or other processes) result in trunk compression. This may be quantified by measuring trunk compression under known change in load. Measurement of subsequent compressions such as that associated with rainfall loading allows quantification of interception water held by the canopy.

[5] Short-term changes in aboveground tree mass are mainly caused by water fluxes, such as (1) water on foliage and bark surfaces, through interception and dew, (2) internal storage changes of water, as triggered by root water uptake and transpiration, and (3) evaporation or dripping of water from the canopy. While aboveground tree mass changes arise because of numerous processes, we focus on canopy interception. Typical values for canopy storage capacity (CSC) fall into the range of $0.3-2.5 \mathrm{~mm}$ for both coniferous

\footnotetext{
${ }^{1}$ Water Resources Section, Faculty of Civil Engineering and Geosciences, Delft University of Technology, Delft, Netherlands.

${ }^{2}$ Department of Electronic Development, Electronic and Mechanical Support Division, Delft University of Technology, Delft, Netherlands.

${ }^{3}$ Department of Biological and Ecological Engineering, Oregon State University, Corvallis, Oregon, USA.
}

Copyright 2008 by the American Geophysical Union. 0043-1397/08/2008WR007074\$09.00 and deciduous tree species [Zhang et al., 2006]. Given a projected crown area of $20 \mathrm{~m}^{2}$ these CSC values correspond to $6-50 \mathrm{~kg}$ of water stored on the tree canopy. The projected crown area is the crown area projected vertically onto the ground. Huang et al. [2005] estimated $52.8 \mathrm{~kg}$ $(\sim 2.64 \mathrm{~mm})$ as a maximum interception capacity for an Araucaria cunninghamia tree using the cantilever method. Internal storage changes of water in trees ranges from $10 \mathrm{~kg} \mathrm{~d}^{-1}$ in moderate climates to $1100 \mathrm{~kg} \mathrm{~d}^{-1}$ in tropical climates [Wullschleger et al., 1998].

[6] The objective of this paper is to present a new measurement technique for direct observations of canopy mass changes. Rainfall interception, as one example for a process causing mass change, will be used to explain the measurement technique. Additional applications of the measurement technique, such as root water uptake, transpiration, changes in biomass, or wind throw observations, are briefly mentioned but are not the focus in this paper.

\section{Methods}

[7] The methods are subdivided into three parts. In section 2.1, the measurement principle, instrument installation, and details of the data logging system are presented. In section 2.2, effects of wind and of temperature on the measurement and on the sensors are explained. In section 2.3, the calibration of the instrument is presented. Section 2.3 further includes calibration results, as well as results from a rainfall interception observation as a sample application of the instrument.

\subsection{Mass Change and Trunk Compression}

[8] Our approach to measure mass change is based on Hooke's law of elasticity. We take a tree trunk to be a linear elastic material. Mass change above the trunk then compresses or expands the tree trunk, resulting in a vertical displacement. The vertical displacement of a tree trunk is determined by the modulus of elasticity of the wood. Moduli of elasticity of green (fresh cut) wood for hardwood species range from 5,200 MPa for Cottonwood to 12,800 MPa for black locust [Green et al., 1999]. For a $1 \mathrm{~kg}$ load the expected compression of a $1 \mathrm{~m}$ tall section of trunk with a $0.01 \mathrm{~m}^{2}$ area and a medium modulus of elasticity of $10,000 \mathrm{MPa}$ would be

$$
\Delta L=\frac{F L}{A E}=\frac{(1[\mathrm{~kg}]) \cdot\left(9.81\left[\mathrm{~m} / \mathrm{s}^{2}\right]\right) \cdot(1[\mathrm{~m}])}{\left(0.01\left[\mathrm{~m}^{2}\right]\right) \cdot\left(10^{9}\left[\mathrm{~N} / \mathrm{m}^{2}\right]\right)} \approx 10^{-7}[\mathrm{~m}] \approx 0.1[\mu \mathrm{m}],
$$



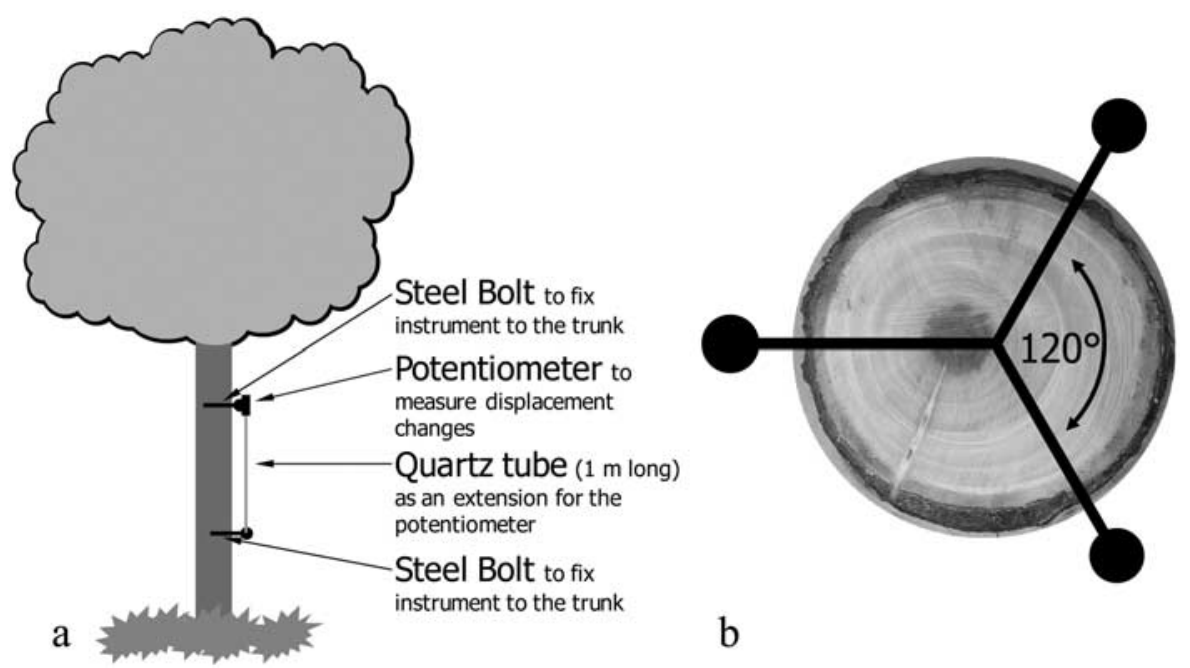

Figure 1. Schematic of sensor installation. The trunk displacement is measured between two steel bolts that are drilled into the tree trunk. (a) Displacement is measured through a potentiometer that is extended by a $1 \mathrm{~m}$ quartz tube. (b) To compensate for bending effect, three sensors are evenly distributed around the trunk.

where $\Delta L$ is the displacement change, $L$ the length of the observed trunk section, $F$ the force or load onto the trunk, $A$ the cross-section area of the trunk, and $E$ the grain-parallel modulus of elasticity of the trunk. Thus a system that could detect $0.1 \mu \mathrm{m}$ of displacement change over a $1 \mathrm{~m}$ trunk section would be sufficient for detecting changes on the order of $1 \mathrm{~kg}$ for a small tree.

[9] The compression of the instrumented trunk section (ITS) was measured with linear motion potentiometers (model 8FLP10A, Feteris Components Benelux, The Hague, Netherlands, $11 \mathrm{~mm}$ range) attached to $1-\mathrm{m}$ quartz tubes ( $\varnothing$ outside $9 \mathrm{~mm}, \varnothing$ inside $2 \mathrm{~mm}$ ) mounted with glue (Pleximon 801, Roehm GmbH, Darmstadt, GER) to the tree with $180 \times 10 \mathrm{~mm}$ steel bolts (Figure 1, with full details provided in the auxiliary material). ${ }^{1}$ The instrument was mounted on a 15-20 year old linden tree, Tilia cordata, growing in the Botanical Garden of TU Delft $\left(52^{\circ} 0^{\prime} \mathrm{N} / 4^{\circ}\right.$ $22^{\prime} \mathrm{E}$ ). The tree had a $9.4 \mathrm{~m}$ height and an average ITS diameter of $0.15 \mathrm{~m}$.

[10] Three sensors were installed with equal radial spacing around the ITS (Figure 1b). We employed a 24-bit (20 effective bits) 15-channel data logger developed by TU Delft. The potentiometers are connected to a buffered output of the data logger's internal reference voltage source, thus achieving a ratiometric measurement that enables us to reach the necessary sensor accuracy and minimize thermal effects on the sensor signal (power supply rejection ratio $>110 \mathrm{~dB}$ ). Near-simultaneous measurements of all three sensors are required and accomplished using track and hold circuits for each sensor. The track and hold circuits improve the switching speed, $\Delta t$, between the single sensor measurements from $\Delta t=0.31 \mathrm{~s}$ to a $\Delta t$ in the nanosecond range. The measurements were found to be accurate to $9.3 \times 10^{-6} \mathrm{~V}$, corresponding to a linear displacement of $0.04 \mu \mathrm{m}$ or a tree mass change of $0.4 \mathrm{~kg}$ (equation (1)). This requires a data

${ }^{1}$ Auxiliary materials are available in the HTML. doi:10.1029/ 2008WR007074. logger capable of 18 effective bits. A mechanically free "dummy" potentiometer was installed next to the three displacement sensors to monitor performance. This potentiometer had a RMSE of $5.1 \times 10^{-6} \mathrm{~V}$, slightly better than the specifications.

\subsection{Wind and Temperature Effects}

[11] In situ measurements in the submicron domain are demanding. Changes in temperature and wind introduce noise, which depends on wood properties and tree geometry.

[12] With temperature increase, both quartz tube and trunk will experience thermal expansion following their coefficients of thermal expansion (CTE). The grain-parallel CTE of dry wood ranges from $4.5-31 \mu \mathrm{m} \mathrm{m}^{-1}{ }^{\circ} \mathrm{C}^{-1}$ [Simpson and TenWolde, 1999]. However, grain-parallel CTE values for living wood are not available in the literature. By controlling the temperature of the ITS, we minimized thermal expansion of the sensors. Sap flow changes the wood temperature. Temperature control aims at maintaining a constant temperature of the three sensors. This will also dampen temperature fluctuations of the trunk that are caused by sap flow. With our installation, it was not possible to add sufficient heat to fully compensate for the cooler water that flows through the sapwood during the day. Separate compensation for measured temperature changes of the trunk and knowledge of the CTE may be necessary. A $20 \mathrm{~m}$ heating wire (PRO POWER VCK8-240V, Telford, United Kingdom) was wound around the ITS, controlled by a centrally located temperature sensor mounted $5 \mathrm{~mm}$ below the bark. The ITS was insolated with several layers of aluminized bubble wrap cushioning material. The bark temperature is thereby held stable within $\pm 0.05^{\circ} \mathrm{C}$. The fused quartz used to span the 1-m ITS was selected for its thermal stability (CTE of $0.59 \mu \mathrm{m} \mathrm{m}^{-1}{ }^{\circ} \mathrm{C}^{-1}$ ).

[13] Wind causes the tree to bend, which expands and compresses the windward and lee sides of the trunk. Single sensor displacements of up to $700 \mu \mathrm{m}$ were measured 

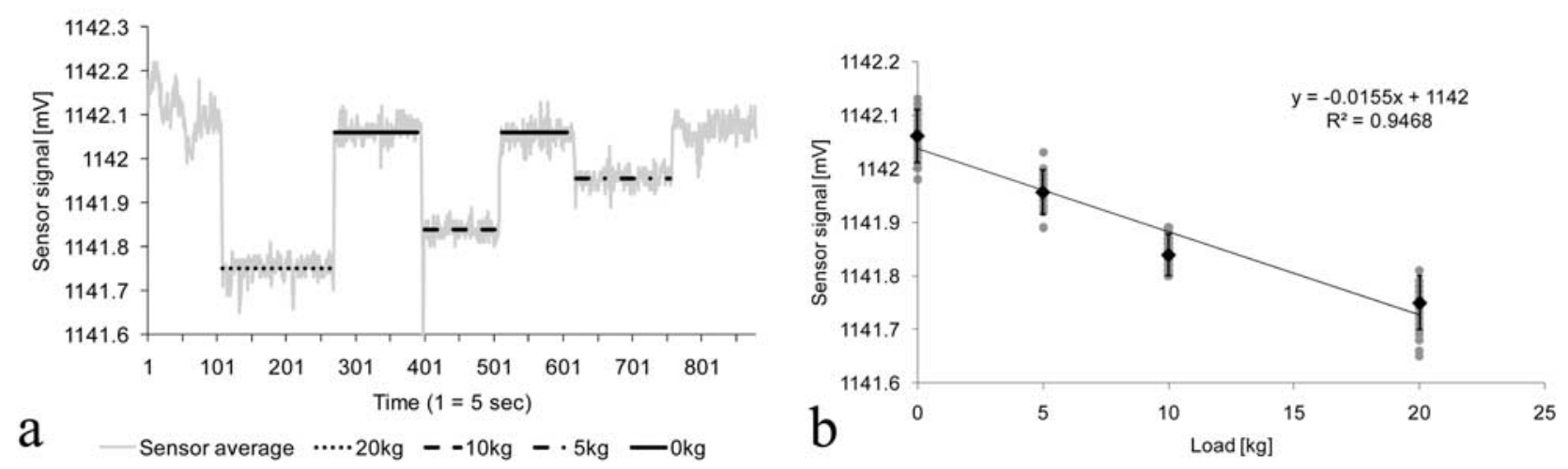

Figure 2. Calibration experiment results for the Tilia cordata experiment: (a) different load periods and the corresponding sensor signal and (b) the associated scatterplot for loads of $0,5,10$, and $20 \mathrm{~kg}$. The error bars are based on 2 standard deviations calculated for each load. The gray dots are the individual measurements, the black dots are the average sensor signals per load, and the black line depicts a linear trend line. From the displacement, the integrated modulus of elasticity of the ITS can be derived.

during the 18 January 2007 Kyrill storm over Europe with wind speeds of up to $75 \mathrm{~km} \mathrm{~h}^{-1}$ (as it was winter, this tree had no leaves). James and Kane [2008] presented an instrument to measure wind load on trees and give a detailed overview of literature in the field of wind throw and tree stability. For a perfectly cylindrical beam, the bending effect can be overcome by evenly distributing three sensors around the beam at equal distances from the geometrical center of the cross section. Averaging the three sensors then compensates for any bending effects. When the tree is bent into the direction of one sensor, the length of that sensor is reduced. The increase in length of the other two sensors then equals exactly $50 \%$ of the decrease of the first sensor, keeping the average the same (Figure $1 \mathrm{~b}$ and auxiliary material). A tree is not a perfect beam but somewhere between the three sensors, there will be a neutral line that does not change length. This neutral line connects the mechanical centers of the cross sections. In a perfect beam, the mechanical and geometrical centers coincide but in a real tree the geometrical center normally differs to some degree from the mechanical center (Figure 1b). When the three sensors are placed at equal distance from the neutral line, averaging will again remove any bending effects. Because we do not know the location of the neutral line before installation, the sensors are equally distributed around the geometrical center. Subsequently, weighting coefficients are employed for each sensor to compensate for the differences between geometrical and mechanical center. The weighted sensors then average out to null the wind effects. Careful placement of the sensors is important to minimize these nonidealities (described in detail in the auxiliary material).

\subsection{Instrument Calibration}

[14] The sensor weighting coefficients may be obtained by analyzing data obtained during a windy period over a few minutes when the leaves of the tree are dry. Under these conditions it is reasonable to assume that there is zero load change, with bending in all directions (though bending along the wind direction will be dominant). Weighting coefficients may be computed as those values that minimize the estimated change in length during the windy period. The weighted average sensor displacements may be computed as

$$
\begin{gathered}
S_{n}^{\prime}=S_{n}-\bar{S}_{n} \\
S_{\text {avg }}^{\prime}=0=\alpha S_{1}^{\prime}+\beta S_{2}^{\prime}+\gamma S_{3}^{\prime} \\
S_{\text {corrected }}=\alpha S_{1}+\beta S_{2}+\gamma S_{3},
\end{gathered}
$$

where $S_{n}$ and $1,2,3$ are the three individual sensors, $\bar{S}_{n}$ the average during the bending experiment per sensor, $\alpha, \beta$, and $\gamma$ the individual weighting coefficients, and $S_{\text {corrected }}$ the corrected average of all three sensors. The weighting coefficients were estimated by minimizing the sum of $S_{\text {avg }}^{\prime 2}$ under the constraint $\alpha+\beta+\gamma=1$.

[15] Once the weighting coefficients are known, the grain-parallel modulus of elasticity may be obtained through calibration. Using equation (1) the displacementweight relationship as well as grain-parallel moduli of elasticity for living wood can be determined. Figure 2 shows calibration results for a medium-sized tree during a windless period. To determine the modulus of elasticity of the ITS, known loads were suspended from the trunk above the ITS. The average sensor signal and standard deviation have been determined from individual measurements during periods of constant load. The duration of each load period was approximately ten minutes with sensor readings every five seconds (Figure 2a). Given the large number of measurements per load (100 to 160) the average signal can be determined with high accuracy. Clearly, the four points do not lie exactly on a straight line (Figure $2 \mathrm{~b}$ ) for which nonlinearities in the system are the most probable cause. On the basis of the four points the standard error in the estimation of the modulus of elasticity is 17 percent. For the Tilia cordata tree onto which the calibration load was applied, the sensitivity is better than $5 \mathrm{~kg}$ (Figure 2b). A displacement-weight conversion factor of $0.1 \mu \mathrm{m} \mathrm{kg}^{-1}$ was found, corresponding to a grain-parallel modulus of elasticity of $5000 \mathrm{MPa}$, in agreement with the value reported by 


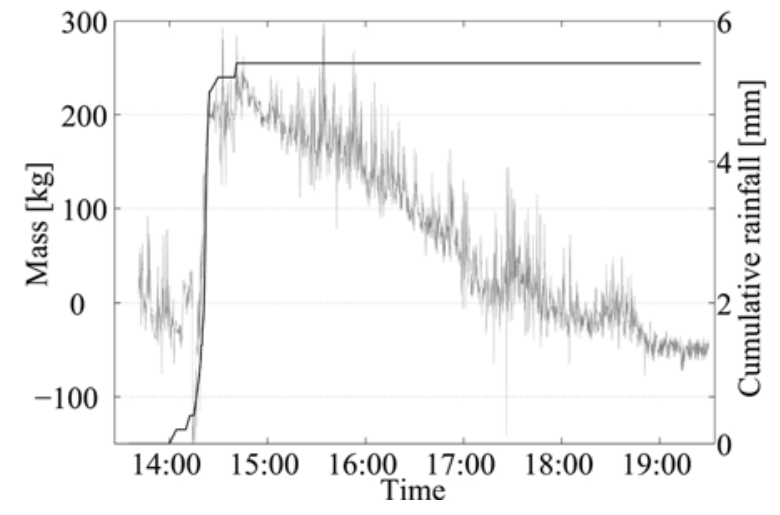

Figure 3. Interception and evaporation (gray line) from a Senna Siamea canopy during a rain event (black line). The gray line depicts the averaged mass derived from three displacement sensors mounted around the trunk. Positive mass change corresponds to a mass gain as caused through interception water.

Brudi [2001]. The accuracy with which the individual calibration points are determined depends on noise levels and number of independent measurements (Figure 2). The calibration test was performed in winter on a Tilia cordata tree without leaves. The sensitivity to load depends linearly on the grain-parallel modulus of elasticity and the average trunk diameter at the ITS, both tree specific, (see equation (1)) as well as on environmental conditions. Given the large effect that wind has, it is recommended to calibrate during wind free periods. For each tree, such a calibration would need to be performed, preferably before and after the experiment. Clearly, the number of different loads has to be increased and it would also be recommended to increase the range of expected loads.

[16] To test the device on a fully leafed-out tree under rainfall conditions, the instruments were mounted on a Senna siamea tree in the northern part of Ghana $\left(10^{\circ} 57^{\prime} 26.7^{\prime \prime} \mathrm{N}, 0^{\circ} 56^{\prime} 30.7^{\prime \prime} \mathrm{W}\right)$. The leaves are pinnate with 9-11 leaflet pairs, $4-5 \mathrm{~cm}$ long and $0.5-2 \mathrm{~cm}$ wide [Hawthorne and Jongkind, 2006]. Tree height was $8.3 \mathrm{~m}$ with a trunk radius of $0.07 \mathrm{~m}$ at the ITS. The projected crown area was $31 \mathrm{~m}^{2}$ and the canopy LAI had an average of 7.7 $(3.6-10.6)$ as determined by an LAI sensor (SunScan, Delta-T Corp, Cambridge, United Kingdom).

[17] On 6 August 2007, a $5.4 \mathrm{~mm}$ convective rainfall event occurred between 1405 and 1445 UT during which the canopy intercepted $\sim 200 \mathrm{~kg}$ (Figure 3). This suggests a canopy storage capacity of at least $6.45 \mathrm{~mm}$, corresponding to a $0.8 \mathrm{~mm} \mathrm{~m}^{-2}$ canopy area based on the LAI. This capacity value is about three times the literature values cited above, which may be due to the properties of the species, the completely different approach employed here (e.g., whole tree in situ versus isolated single branch), or errors in calibration. Data peaks before the rain event are most probably due to high wind speeds which can cause bending that is not completely nulled by the sensor distribution around the bark. In addition to bending, strong wind can also temporarily cause an actual lift of the canopy. The mismatch between observed rainfall and intercepted canopy water is due to the accumulation of errors in calibration and uncertainties in LAI, projected crown area, and rainfall measurements. Means to achieve a fully quantified calibration need to be specifically developed. It should also be noted that root water uptake has not been considered but might play a role in the interpretation of the results.

\section{Conclusions}

[18] We have presented a proof of concept of a measurement technique for direct, nondestructive, and continuous observation of aboveground tree mass. The data shown are, to our knowledge, the first nondestructive method for directly measuring trees in their natural setting. As a sample application we have presented data from a rainfall interception event. Additional applications might include transpiration and root water uptake studies, as well as biomechanical studies, such as wind throw. Applications all require different data processing, as for example signal noise for one application are observation data for another application. In terms of canopy interception, further development of the mounting method, field calibration, and postprocessing (e.g., temperature correction, and sensor weighting) will be required to make this approach fully operational.

[19] Acknowledgments. This research is part of the GLOWA Volta Project funded by the German Ministry of Education and research (BMBF) and the federal state Northrhine-Westphalia (NRW) and of the PEP MetOp for Drymon project funded by the Netherlands Agency for Aerospace Programmes (NIVR). The authors would especially like to thank the director, Bob Ursem, and the staff of the Botanical Garden of TU Delft for the possibility of using their facilities and their continuous support. We would also like to thank the editor and the reviewers for their helpful and clarifying comments.

\section{References}

Aston, A. R. (1979), Rainfall interception by 8 small trees, J. Hydrol., 42(3-4), 383-396, doi:10.1016/0022-1694(79)90057-X

Bouten, W., P. J. F. Swart, and E. de Water (1991), Microwave transmission, a new tool in forest hydrological research, J. Hydrol., 124(1-2), 119-130, doi:10.1016/0022-1694(91)90009-7.

Brudi, E. (2001), Longitudinal prestresses in Tilia cordata and Acer pseudoplatanus, M.Sc. thesis, Univ. of Aberdeen, Aberdeen, U. K.

Edwards, W. R. N. (1986), Precision weighing lysimetry for trees, using a simplified tared-balance design, Tree Physiol., 1, 127-144.

Forgeard, F., J. C. Gloaguen, and J. Touffet (1980), Interception des précipitations et apport au sol d'élèments mineraux par les eaux de pluie et les pluviolessivats dans une hêtraie atlantique et dans quelques peuplements résineux en Bretagne, Ann. Sci. For., 37(1), 53-71, doi:10.1051/ forest: 19800104 .

Fritschen, L. J., L. Cox, and R. Kinerson (1973), A 28-meter Douglas-fir in a weighing lysimeter, For. Sci., 19, 256-261.

Granier, A. (1987), Sap flow measurements in Douglas-fir tree trunks by means of a new thermal method, Ann. Sci. For., 44(1), 1-14, doi:10.1051/forest:19870101.

Green, D. W., J. E. Winandy, and D. E. Kretschmann (1999), Mechanical properties of wood, in Wood Handbook-Wood as an Engineering Material, Gen. Tech. Rep. FPL, vol. 113, pp. 4-1-4-45, For. Products Lab., U.S. Dep. of Agric., Madison, Wis.

Green, S. R., and B. E. Clothier (1988), Water use of kiwifruit vines and apple trees by the heat-pulse technique, J. Exp. Bot., 39(1), 115-123, doi:10.1093/jxb/39.1.115.

Hancock, N. H., and J. M. Crowther (1979), A technique for the direct measurement of water storage on a forest canopy, J. Hydrol., 4l(1-2), 105-122, doi:10.1016/0022-1694(79)90109-4.

Hawthorne, W. D., and C. C. H. Jongkind (2006), Woody Plants of Western African Forests. A Guide to the Forest Trees, Shrubs and Lianes From Senegal to Ghana, Kew, London.

Huang, Y. S., S. S. Chen, and T. P. Lin (2005), Continuous monitoring of water loading of trees and canopy rainfall interception using the strain gauge method, J. Hydrol., 311(1-4), 1-7, doi:10.1016/j.jhydrol. 2004.08.036. 
James, K. R., and B. Kane (2008), Precision digital instruments to measure dynamic wind loads on trees during storms, Agric. Meteorol., 148(6-7), 1055-1061, doi:10.1016/j.agrformet.2008.02.003.

Keim, R. F., A. E. Skaugset, and M. Weiler (2006), Storage of water on vegetation under simulated rainfall of varying intensity, Adv. Water Resour., 29(7), 974-986, doi:10.1016/j.advwatres.2005.07.017.

Llorens, P., and F. Gallart (2000), A simplified method for forest water storage capacity measurement, J. Hydrol., 240(1-2), 131-144, doi:10.1016/S0022-1694(00)00339-5.

Navar, J., and R. Bryan (1990), Interception loss and rainfall redistribution by three semi-arid growing shrubs in northeastern Mexico, J. Hydrol., 115(1-4), 51-63, doi:10.1016/0022-1694(90)90197-6.

Oguntunde, P. G., and N. van de Giesen (2005), Water flux measurement and prediction in young cashew trees using sap flow data, Hydrol. Processes, 19(16), 3235-3248, doi:10.1002/hyp.5831.

Savenije, H. H. G. (2004), The importance of interception and why we should delete the term evapotranspiration from our vocabulary, Hydrol. Processes, 18(8), 1507-1511, doi:10.1002/hyp.5563.

Sevanto, S., T. Vesala, M. Peramaki, J. Pumpanen, H. Ilvesniemi, and E. Nikinmaa (2001), Xylem diameter changes as an indicator of standlevel evapo-transpiration, Boreal Environ. Res., 6(1), 45-52.

Simpson, W., and A. TenWolde (1999), Physical properties and moisture relations of wood, in Wood Handbook-Wood as an Engineering Mate- rial, Gen. Tech. Rep. FPL, vol. 113, pp. 3-1-3-24, For. Products Lab., U.S. Dep. of Agric., Madison, Wis.

Storck, P., D. P. Lettenmaier, and S. M. Bolton (2002), Measurement of snow interception and canopy effects on snow accumulation and melt in a mountainous maritime climate, Oregon, United States, Water Resour. Res., 38(11), 1223, doi:10.1029/2002WR001281.

Wullschleger, S. D., F. C. Meinzer, and R. A. Vertessy (1998), A review of whole-plant water use studies in trees, Tree Physiol., 18(8-9), 499-512.

Zhang, G., G. M. Zeng, Y. M. Jiang, G. H. Huang, J. B. Li, J. M. Yao, W. Tan, R. Xiang, and X. L. Zhang (2006), Modelling and measurement of two-layer-canopy interception losses in a subtropical evergreen forest of central-south China, Hydrol. Earth Syst. Sci., 10(1), 65-77.

J. Friesen, H. H. G. Savenije, and N. van de Giesen, Water Resources Section, Faculty of Civil Engineering and Geosciences, Delft University of Technology, Stevinweg 1, NL-2628 CN Delft, Netherlands. (j.c.friesen@ tudelft.nl)

J. Selker, Department of Biological and Ecological Engineering, Oregon State University, 116 Gilmore Hall, Corvallis, OR 97331, USA.

C. van Beek, Department of Electronic Development, Electronic and Mechanical Support Division, Delft University of Technology, P.O. Box 5048, NL-2600 GA Delft, Netherlands. 